\title{
Column study of benzene adsorption onto activated carbon
}

\author{
C.L. Chuang ${ }^{\mathrm{a}}$, P.C. Chiang ${ }^{\mathrm{a}, *}$, E.E. Chang ${ }^{\mathrm{b}}$ \\ ${ }^{a}$ Graduate Institute of Environmental Engineering, National Taiwan University, Taipei, Taiwan \\ ${ }^{\mathrm{b}}$ Department of Biochemistry, Taipei Medical University, Taipei, Taiwan
}

Received 3 October 2001; accepted 26 March 2003

Activated carbon, due to its high specific surface area, has been used extensively as an adsorbate for removal of hazardous air pollutants. Most of the column adsorption studies were conducted at a specific temperature, and the major methods of data analysis include: a linear driving force approximation [1-5], an empirical method [6], and thermodynamic equilibrium [7,8]. The linear driving force model considers adsorption as an irreversible reaction. As for the thermodynamic equilibrium method, an ideal adsorbed solution theory was based on the thermodynamic equivalence of each solute at equilibrium.

These methods suffer from different disadvantages, e.g. the thermodynamic equilibrium method considers only adsorption under equilibrium conditions; the linear driving force method accounts for adsorption only, and an empirical method is always short of theoretical considerations. In reality adsorption is rarely at equilibrium and both adsorption and desorption occur at the same time. Consequently, the objective of this investigation is to develop a thermodynamic model with a non-linear driving force in conjunction with the Langmuir model for predicting the effect of operating conditions. The developed model is also able to predict adsorption isotherms and adsorption breakthrough under different conditions, and provide the detailed reaction rate changes in the adsorption process.

The original activated carbon (Sorbonorit 3, Norit, The Netherlands) was ground and sieved to obtain 35-45 mesh particles and then was heated to $573 \mathrm{~K}$ and treated with nitrogen gas over $24 \mathrm{~h}$ to remove the contaminants. For each test, about $2 \mathrm{~g}$ of treated activated carbon was packed in a small glass column, about $3 \mathrm{~cm}$ in length and $1.5 \mathrm{~cm}$ in diameter. The column diameter was designed as over 30 times the particle diameter to prevent the occurrence of short circuiting, and the length of the $3-\mathrm{cm}$ column was used to provide a well-developed adsorption zone. Ben-

*Corresponding author. Fax: + 886-2-2366-1642.

E-mail address: pcchaing@ntu.edu.tw (P.C. Chiang). zene vapor was generated by a VOC generator and carried by dehydrated and dehydrocarboned nitrogen gas. The packed column temperature and benzene temperature were controlled by a thermostat and maintained constant for $3 \mathrm{~h}$ under nitrogen flow before the test. The flow rate was controlled at $1.21 \mathrm{~min}^{-1}$ by a mass flow meter, and benzene concentration was measured by gas chromatography with a flame ionization detector.

Based on the Langmuir model, the reaction rate $(R)$ in the solid phase is equal to the adsorption rate $\left(R_{\mathrm{a}}\right)$ minus desorption rate $\left(R_{\mathrm{d}}\right)$, i.e.:

$\frac{\partial \theta}{\partial t}=R_{\mathrm{a}}-R_{\mathrm{d}}=k_{\mathrm{a}}(1-\theta) C-k_{\mathrm{d}} \theta$

where $\theta$ is the saturation coverage of VOC on the activated carbon surface, equal to adsorption capacity $(q)$ over monolayer capacity $\left(q_{0}\right), k_{\mathrm{a}}$ is the adsorption rate constant $\left(\mathrm{m}^{3} \mathrm{~s}^{-1} \mathrm{~mol}^{-1}\right)$, and $k_{\mathrm{d}}$ is the desorption rate constant $\left(\mathrm{s}^{-1}\right)$. The VOC concentration changes in the gas phase include gas phase transport, adsorption and desorption process, assuming no diffusion limitations:

$\frac{\partial C}{\partial t}=-U \frac{\partial C}{\partial L}-\frac{\partial \theta}{\partial t} S$

Here $U$ is the gas velocity ( $\mathrm{m} \mathrm{s}^{-1}$ ) and $L$ is the length of adsorption bed $(\mathrm{m}) . S$ is the exchange factor $\left(\mathrm{g} \mathrm{m}^{-3}\right)$ between solid phase and gas phase, $q_{0} W /(L A-W / \rho)$, where $W$ is the weight of activated carbon $(g), A$ the cross-sectional area of adsorption bed $\left(\mathrm{m}^{2}\right)$, and $\rho$ the density of activated carbon $\left(\mathrm{g} \mathrm{m}^{-3}\right)$

Considering the activated carbon bed as a series of continuous-flow stirred tank reactors (CFSTRs), the adsorption process can be described by the Langmuir isotherm and adsorption desorption process [9]. Let the activated carbon bed be a $n$-series $(n=50)$ of CFSTRs, and each reaction time in one unit is $\Delta t$. In the $i$ th unit, the 


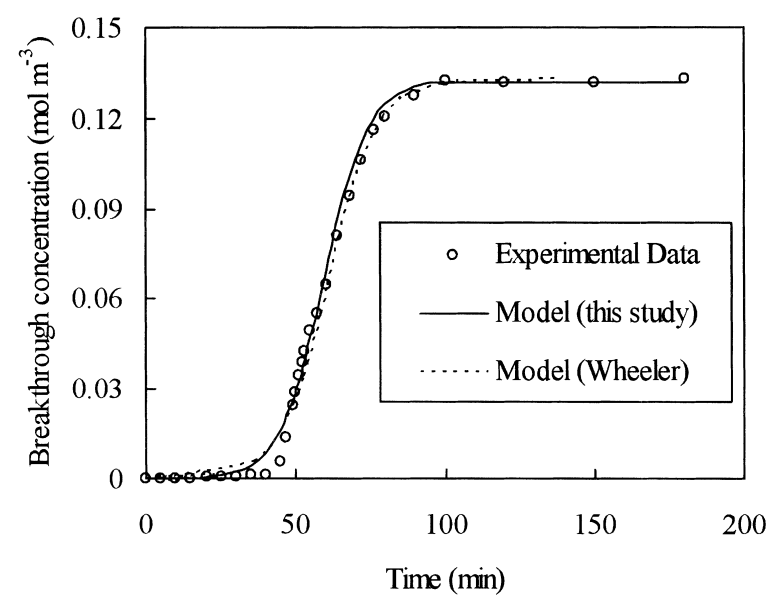

Fig. 1. Simulated breakthrough curve for two models $(T=303 \mathrm{~K})$.

concentration change in solid and gas phases can be determined by a finite difference method as follows:

$$
\begin{aligned}
\theta_{i}^{t+\Delta t}= & \theta_{i}^{t}+\left[k_{\mathrm{a}}\left(1-\theta_{i}^{t}\right) C_{i}^{t}-k_{\mathrm{d}} \theta_{i}^{t}\right] \Delta t \\
C_{i}^{t+\Delta t}= & C_{i}^{t}+\frac{Q \Delta t}{\Delta V}\left(C_{i}^{t}-C_{i-1}^{t}\right) \\
& +\left[-k_{\mathrm{a}}\left(1-\theta_{i}^{t}\right) C_{i}^{t}+k_{\mathrm{d}} \theta_{i}^{t}\right] S \Delta t
\end{aligned}
$$

Here $Q$ is the flow rate $\left(\mathrm{m}^{3} \mathrm{~s}^{-1}\right)$, equal to $U A-U A W /$ $(\rho L A)$; and $V$ is the gas phase volume $\left(\mathrm{m}^{3}\right)$ in each unit of CFSTR, equal to $(L A-W / \rho) / n$. Based on the above finite difference equations and parameters $k_{\mathrm{a}}$ and $k_{\mathrm{d}}$, the adsorption process in the activated carbon bed can be simulated.

In this study the Langmuir, Freundlich and Redlich-
Peterson model were used to simulate the isotherm (303 $\mathrm{K})$ :

Langmuir:

$$
\begin{aligned}
q\left(g g^{-1}\right) & =\frac{q_{0} K_{\mathrm{L}} C_{0}}{1+K_{\mathrm{L}} C_{0}} \\
& =\frac{0.46 \times 39.8 \times C_{0}}{1+39.8 \times C_{0}} ; \\
R^{2} & =0.99
\end{aligned}
$$

Freundlich:

$$
\begin{aligned}
q\left(g g^{-1}\right) & =K_{\mathrm{F}} C_{0}^{n}=0.88 \times C_{0}^{0.38} ; \\
R^{2} & =0.97
\end{aligned}
$$

Redlich-Peterson: $\quad q\left(g g^{-1}\right)=\frac{K_{\mathrm{R}} C_{0}}{B+C_{0}^{m}}$

$$
\begin{aligned}
& =\frac{0.44 \times C_{0}}{0.03+C_{0}^{1.03}} ; \\
R^{2} & =0.99
\end{aligned}
$$

The results indicate that these models can reasonably describe the experimental data. For simplicity, the Langmuir model was chosen to describe the state of adsorption and desorption because the numerical model in this study was based on the Langmuir model.

The best fit was evaluated by the root mean square error, $\varepsilon$, between breakthrough concentration, $C_{\mathrm{b}}$, and predicted concentration, $C^{\prime}$.

\begin{tabular}{|c|c|c|c|c|c|c|}
\hline Conditions and parameters & Unit & Run 1 & Run 2 & Run 3 & Run 4 & Run 5 \\
\hline Temperature, $T$ & $\mathrm{~K}$ & 283 & 303 & 323 & 343 & 363 \\
\hline Weight of carbon, $W$ & $\mathrm{~g}$ & 2.001 & 2.005 & 2.001 & 2.002 & 2.001 \\
\hline Length of carbon bed, $L$ & $\mathrm{~cm}$ & 3.0 & 3.1 & 3.0 & 3.0 & 3.0 \\
\hline Concentration, $C_{\mathrm{o}}$ & $\mathrm{mmol} \mathrm{m}^{-3}$ & 116 & 133 & 108 & 103 & 88 \\
\hline Saturation concentration, $C_{\text {sat }}$ & $\mathrm{mol} \mathrm{m}^{-3}$ & 2.6 & 6.3 & 13.5 & 25.8 & 45.1 \\
\hline Flow rate, $Q$ & $1 \min ^{-1}$ & 1.14 & 1.20 & 1.30 & 1.38 & 1.46 \\
\hline Retention time ${ }^{* *}, t$ & $\mathrm{~s}$ & 0.161 & 0.159 & 0.141 & 0.133 & 0.125 \\
\hline Adsorption rate constant, $k_{\mathrm{a}}$ & $\mathrm{m}^{3} \mathrm{~s}^{-1} \mathrm{~mol}^{-1}$ & 0.013 & 0.016 & 0.019 & 0.040 & 0.060 \\
\hline Desorption rate constant, $k_{\mathrm{d}}$ & $\mathrm{s}^{-1}$ & $1.0 \times 10^{-4}$ & $4.4 \times 10^{-4}$ & $1.7 \times 10^{-4}$ & $5.0 \times 10^{-3}$ & $1.1 \times 10^{-2}$ \\
\hline Equilibrium constant, $K$ & $\mathrm{~m}^{3} \mathrm{~mol}^{-1}$ & 130 & 36.6 & 11.7 & 8.0 & 5.4 \\
\hline Arrhenius equation & & \multicolumn{5}{|c|}{$\begin{array}{l}\ln \left(k_{\mathrm{a}}\right)=-2005 / T+2.6 ; R^{2}=0.91 \\
\ln \left(k_{\mathrm{d}}\right)=-6.12 / T+12.5 ; R^{2}=0.99\end{array}$} \\
\hline Measured number in each test, $N$ & - & 27 & 29 & 41 & 32 & 26 \\
\hline Root mean square error, $\varepsilon$ & - & 0.02 & 0.03 & 0.03 & 0.05 & 0.04 \\
\hline
\end{tabular}

$\varepsilon=\frac{1}{C_{0}} \sqrt{\frac{1}{N} \sum_{n=1}^{N}\left(C_{\mathrm{b}}-C^{\prime}\right)^{2}}$

where $N$ is the measured number in each test.

Fig. 1 presents the simulation result from this model, as well as the Wheeler model at $303 \mathrm{~K}$. The results are summarized in Table 1. Clearly, the model reasonably

Table 1

Adsorption conditions, parameters and statistics for each adsorption experiment at density of $880 \mathrm{~kg} \mathrm{~m}^{-3}$, bed cross-section area of $1.76 \mathrm{~cm}^{2}$ and unit layer capacity of $460 \mathrm{mg} \mathrm{g}^{-1}$

* Ref. [10] ** $\tau=\frac{(L A / W \rho)}{Q}$ 


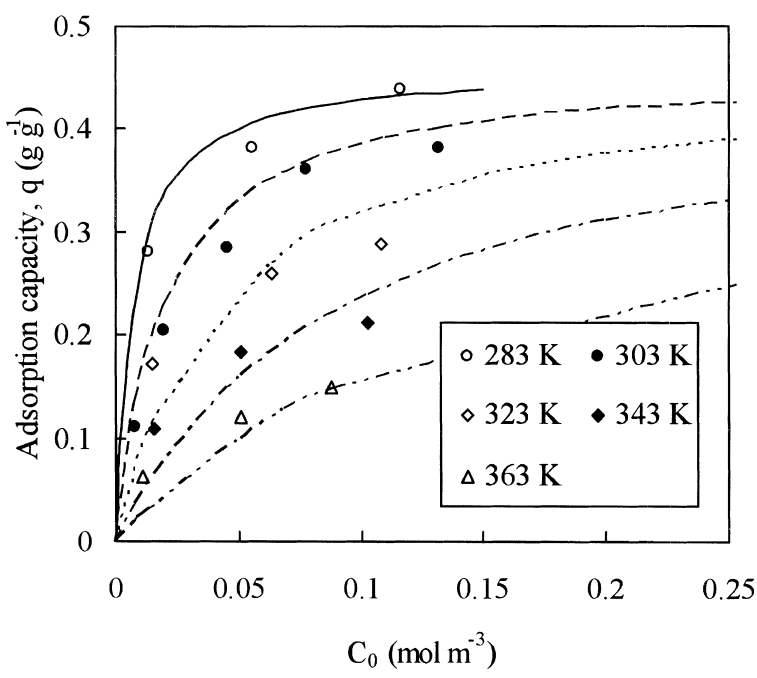

Fig. 2. Curve fitting of adsorption isotherm at different conditions.

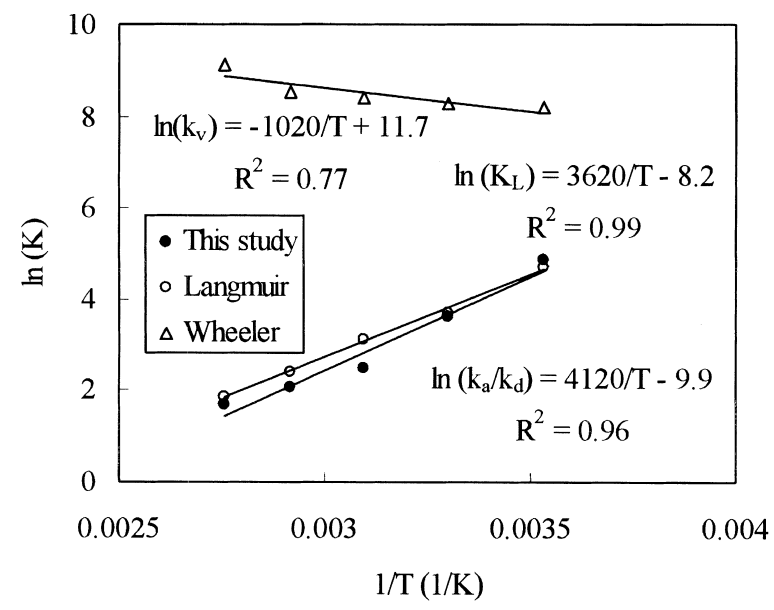

Fig. 3. Relationship between adsorption parameters and temperature.

matches the observed data. As expected, both $k_{\mathrm{a}}$ and $k_{\mathrm{d}}$ increase with temperature along with a decrease in equilibrium constant $\left(K=k_{\mathrm{a}} / k_{\mathrm{d}}\right)$. Fig. 2 shows the isotherm simulation at various operating conditions.

Based on the Arrhenius equation, the adsorption activation energy $\left(E_{\mathrm{a}}\right)$ and the desorption activation energy $\left(E_{\mathrm{d}}\right)$ were determined as 4.0 and $12.2 \mathrm{kcal} \mathrm{mol}^{-1}$. Consequently, the heat of adsorption of $\mathrm{C}_{6} \mathrm{H}_{6}$ is $-8.2 \mathrm{kcal}$ $\mathrm{mol}^{-1}$. Fig. 3 shows the relationship of rate constants with temperature. Also the $\ln (K)$ values of our model and the Langmuir model have a better relationship with $1 / T$ than those of the Wheeler model. Our equilibrium constants are of the same order of magnitude as those of the Langmuir model.
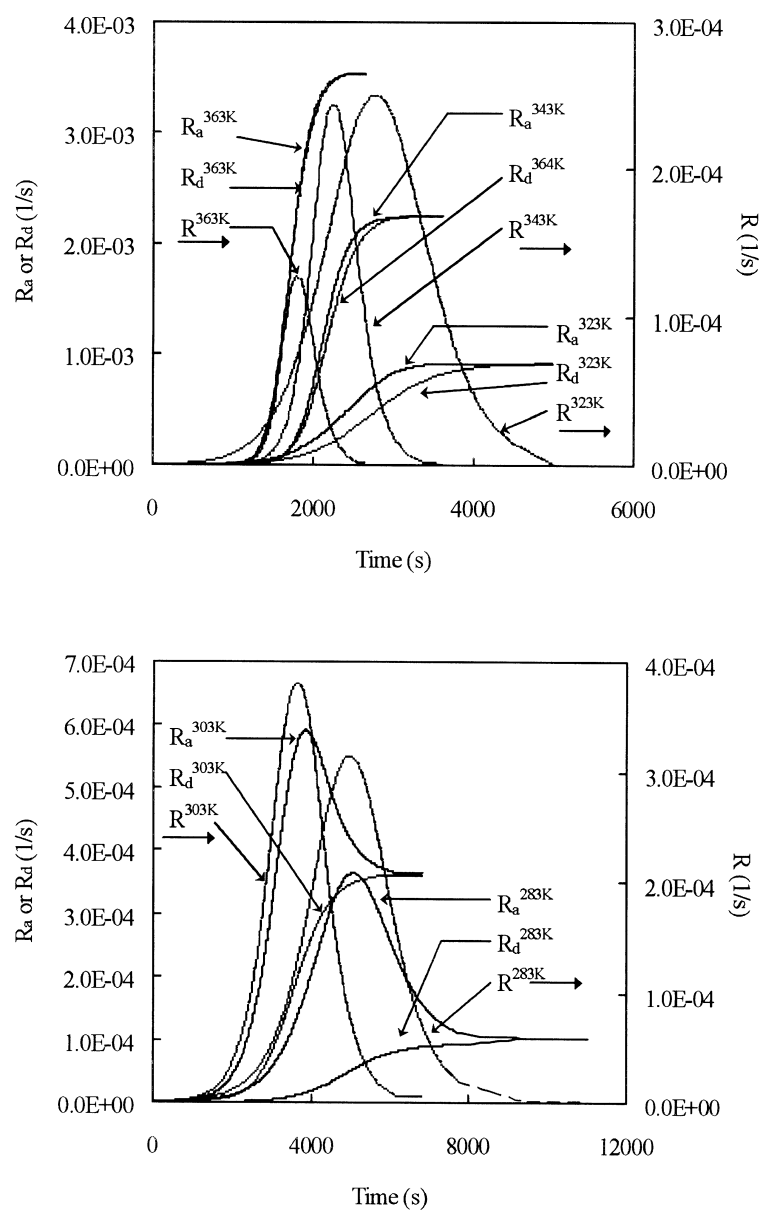

Fig. 4. Adsorption and desorption rate changes with the progress of adsorption process. (Operation conditions: Table 1).

The adsorption and desorption rate constants can be used to predict the progress of the adsorption process. The trends in Fig. 4 are of course affected by temperature. The net reaction is also a function of temperature, and when the adsorption process approaches equilibrium (i.e. $R_{\mathrm{a}}=R_{\mathrm{d}}$ ), the adsorption rate (or desorption rate) at high temperature is higher than at low temperatures, as expected. At higher temperatures (3231, 343 and $363 \mathrm{~K}$; Fig. 4, top), the adsorption rate appears to be slightly higher than the desorption rate. At low temperatures (283 and 303 K; Fig. 4 , bottom), the adsorption rate is much higher than the desorption rate.

An activated carbon bed adsorption process is also influenced by surface characteristics of the adsorbent and the characteristics and concentration of VOC. In this study, the proposed mathematical model could predict the adsorption isotherms and breakthrough curves under various conditions. A high temperature would increase the rates and thus decrease the adsorption efficiency. We not only show the same trend as the Wheeler and Langmuir models, 
but also extract other pertinent parameters of the adsorption process.

\section{References}

[1] Vahdat N, Swearengen PM, Johnson JS, Priante S, Mathews $\mathrm{K}$, Neihart A. Adsorption capacity and thermal desorption efficiency of selected adsorbents. Am Ind Hyg Assoc J 1995;56(1):32-8.

[2] Jonas LA, Rehmann JA. The Kinetics of adsorption of organo-phosphorus vapors from air mixtures by activated carbon. Carbon 1972;10(6):657-63.

[3] Malek A, Farooq S. Kinetics of hydrocarbon adsorption on activated carbon and silica gel. AIChE J 1997;43(3):761-76.

[4] Malek A, Faroog S, Rathor MN, Hidajat K. Effect of velocity variation due to adsorption-desorption on equilibrium data from breakthrough experiments. Chem Eng Sci 1995;50(4):737-40.
[5] Vahdat N. Theoretical study of the performance of activated carbon: in the presence of binary vapor mixtures. Carbon 1997;35(10):1545-57.

[6] Yoon YH, Nelson JH. Application of gas adsorption kinetics: I. A theoretical model for respirator cartridge service life. Am Ind Hyg Assoc J 1984;45(8):509-16.

[7] Myers AL, Valenzuela DP. Computer algorithm and graphical method for calculating adsorption equilibria of gas mixtures. J Chem Eng Jpn 1986;19(5):392-6.

[8] Pigram PJ, Lamb RN, Hibbert DB, Collins RE. Modeling of the desorption behavior of microporous amorphous hydrogenated carbon films. Langmuir 1994;10(1):142-7.

[9] Jørgenson RB, Bjørseth O. Sorption behaviour of volatile organic compounds on material surfaces - the influence of combinations of compounds and materials compared to sorption of single compounds on single materials. Environ Int 1999;25(1):17-27.

[10] Boublik T, Fried V, Hala E, editors, The vapor pressure of pure substances, New York: Elsevier Scientific Publishing Company; 1973, p. 257.

\title{
Optical properties of pyrolytic carbon deposits deduced from measurements of the extinction angle by polarized light microscopy
}

\author{
E.G. Bortchagovsky ${ }^{\mathrm{a}, *}$, B. Reznik ${ }^{\mathrm{b}}$, D. Gerthsen ${ }^{\mathrm{b}}$, A. Pfrang ${ }^{\mathrm{c}}$, Th. Schimmel $^{\mathrm{c}}$ \\ ${ }^{a}$ Institute of Semiconductor Physics, pr. Nauki 45, Kiev 03022, Ukraine \\ ${ }^{\mathrm{b}}$ Laboratorium für Elektronenmikroskopie, Universität Karlsruhe, 76128 Karlsruhe, Germany \\ ${ }^{\mathrm{c}}$ Institut für Angewandte Physik, Universität Karlsruhe, 76128 Karlsruhe, Germany
}

Received 14 April 2003; accepted 12 June 2003

Keywords: A. Pyrolytic carbon; C. Optical microscopy; D. Optical properties

The physical properties of graphite are considered a limit of the crystallization degree of pyrolytic carbon deposits. For instance, the spacing of basal planes of graphite is $0.335 \mathrm{~nm}$ while for pyrolytic carbon deposits it varies from 0.344 to $0.335 \mathrm{~nm}$ as annealing temperature increases [1]. The ratio of $\pi$ - and $\sigma$-bonding electronic states in graphite is $1 / 3$, and the deviation from this value can be related to different texture degrees of pyrolytic carbon matrices of infiltrated carbon felts [2].

On the contrary to other optical investigations [3] this correlation between graphite and pyrolytic carbon is not valid for polarized light microscopy, which is based on the optical anisotropy of pyrolytic carbon deposits and has been a benchmark for the rapid characterization of the

\footnotetext{
*Corresponding author. Tel.: +380-44-265-9706; fax: +38044-265-8342.

E-mail address: evgen@system.semicond.kiev.ua (E.G. Bortchagovsky).
}

texture degree of such materials for a long time. The measured extinction angles $A_{\mathrm{e}}$ for deposits usually exhibit values up to $A_{\mathrm{e}} \approx 24^{\circ}$ [4], which are significantly higher than the value of $16.3^{\circ}$ reported for graphite [5] (Fig. 1). As graphite is considered the limit of the texture degree of pyrolytic carbon, the extinction angle of pyrolytic carbon is supposed to approach the value for graphite which is seemingly not the case.

This article is devoted to clarifying this apparent contradiction and presents a short discussion of the physical meaning of the $A_{\mathrm{e}}$ value and its connection to the physical parameters of the systems of interest.

To compare values measured for graphite and pyrolytic carbon, we have to consider the structure of samples and the background of the applied methods. While graphite is a uniaxial crystal with the optical axis along the [001] direction (Fig. 2a), pyrolytic carbon is usually measured being deposited on substrates with rotational symmetry like carbon fibers. Deposited carbon domains have aro- 